THURSDAY, APRIL 9, 1908.

\section{EXPERIMENTAL EMBRYOLOGY.}

Experimental-Zoologie. Part i. Embryogenese. Eine Zusamnenfassung der durch Versuche ermittelten Gesetzmässigkeiten tierischer Ei-Entwicklung (Befruchtung, Furchung, Organbildung). By Dr. Hans Przibram. Pp. 125; 16 plates. (Leipzig und Wien: Franz Deuticke, 1907.) Price 7 marks.

COME three years ago Dr. Przibram, who is well $\checkmark$ known as a brilliant representative of the school of experimental zoologists, published "An Introduction to Experimental Morphology," which met with wide acceptance. The present volume is an expansion of part of the "Introduction," and forms an independent treatise on experimental embryology. It is to be followed by four other parts, dealing with regeneration, evolution, vitality, and function, and the whole will form a text-book of experimental zoology. If the subsequent parts are like the one before us in lucidity and thoroughness, Dr. Przibram will earn the gratitude of all interested in this dynamic aspect of the science; and who, nowadays, can afford to stand aloof? The present volume discusses, in the light of experimental results, the processes of fertilisation, cleavage, gastrulation, and differentiation, and sums up in an analysis of the influence of chemical stimuli, moisture, density of the medium, pressure, rravity, electricity and magnetism, light and heat. There is a copious and carefully executed bibliography, and the figures in the plates, which are partly compiled and partly original, are very clear and interesting.

The author discusses large and difficult problems, in regard to which there is room for considerable difference of opinion, but his treatment of these is thoroughly objective and undogmatic. We cannot do better than give some samples of his general conclusions. Fertilisation, whether artificial or spermatic, brings about a withdrawal of water from the egg; this accelerates the vital processes which are going on of themselves, and the egg passes from a relatively resting state to progressive development. The unfertilised egg has an organisation of different kinds of substances which guarantees the forthcoming manifoldness. The direction of the first cleavage is in a plane at right angles to the axis of the first karyokinetic spindle, and the position of the latter is determined by the geometrical architecture of the egg and the fertilisation-meridian (on which the spermatozoon enters).

In regard to the familiar sequence of centrosome division, astrosphere formation, nuclear division, cytoplasmic division, and perhaps also the progressive differentiation of the blastomeres, we must not suppose that any particular link in the chain is the necessary cause of the next link; we must rather suppose that a common cause evolses them in succession, and that their cooperation secures the typical development. Provisionally we may say that the common cause of the mitotic phenomena lies in a localised change in

No. 2006 voL. 77] the fluidity of the enchylemma and the associated rearrangement of a monocentric into a dicentric surfacetension-system. The second and subsequent cleavages depend on a rhythmic recurrence of the metabolic relations involved in the first cleavage (the entrance of oxygen conditioning the continuance of the metabolism, the intensity of which changes with the changes in the proportion of absorbent surface to assimilatory volume), and on the presence of antagonistic substances, which partly prevent the complete separation of the blastomeres (calcium), and partly secure a certain cohesion (sodium).

The arrangement of the blastomeres depends on Plateau's law of the smallest surface, modified by differences in the consistence of different parts of the ovum, which are also responsible for the different sizes of the blastomeres (Balfour's law). Blastulation and gastrulation depend on chemotactic influences, which are set at work by metabolic processes, and admit not only of passive-mechanical displacements, but of active migrations as well. In different zones of the egg there are chemically different substances which normally condition the differentiation of the various organs. Thus the blastomeres acquire a prospective value. If there is no rearrangement of material, an artificial fractioning of the egg is followed by a self-differentiation of the fragments, so that semi-embryos, quarto-embryos, and so on, result; but if a re-arrangement is effected, restoring the status quo of the intact ovum, then dwarf complete embryos result. The prospective potency of such blastomeres is greater than their prospective value. The influence of external factors is subsidiary when compared with the internal formative factors, and animal embryogenesis may be described as an almost quite perfect self-differentiation in Roux's sense.

We have stated these general conclusions because of their great interest, but it must be noted that the bulk of the book is a terse statement of concrete facts from which the expert student may draw his own conclusions, and at this stage that is well.

\section{J. A. T}

\section{GEOLOGICAL REVIVALISM.}

Geologische Prinzipienfragen. By E. Reyer. Pp. $\mathrm{x}+202$. (Leipzig: W. Engelmann, 1907.) Price 4.40 marks.

THIS work recalls, with renewed interest, a remarkable paper by Mr. Reyer on the Schlossberg of Teplitz, to which the attention of the present writer was directed by Prof. Judd nearly thirty years ago. Are not some of Reyer's models still preserved in London, and have not these models, and respectful visits to the Schlossberg itself, influenced many of us in our attempts at teaching ever since? Mr. Rever, however, when he went further into the theory of the formation of mountains by the protrusion of masses from below and the gliding of the superincumbent layers, found the geological world opposed to him, and he turned, as he now informs us (p. v.), to fields of sociological activity. Yet he should surely be satisfied with the numerous references to his 